development of children can be clarified and reported to a risk management bureau, appropriate risk management steps, such as self-imposed restraints, examination chemical compound control, and the implementation of environmental quality standards in water and soil, can be applied.

Methods Investigation scale: 100000 pregnant mothers and their children from across Japan (we plan to enrol 6840 pregnant mothers from Fukushima City, South Soma City, and Futaba County). Investigation period: 16 years ( 3 for recruitment, 13 for tracking) commencing 31 January 2011.

Results and Conclusion Recruitment number and rate in a half year will be presented. The prospects of Japan Eco \& Child Study in Fukushima will be also described in presentation. It is important to discuss the problems on long term study.

\section{SP3-35 INVESTIGATING DENTAL TREATMENT AS A POSSIBLE RISK FACTOR FOR VARIANT CREUTZFELDT-JAKOB DISEASE (VCJD) IN THE UK}

doi:10.1136/jech.2011.1429760.35

${ }^{1} \mathrm{~A}$ Smith, ${ }^{2} \mathrm{D}$ Everington, ${ }^{2} \mathrm{P}$ Watt, ${ }^{2} \mathrm{~F}$ Ord, ${ }^{2} \mathrm{~A}$ Molesworth, ${ }^{* 2} \mathrm{R}$ Will, ${ }^{2} \mathrm{H}$ Ward. ${ }^{1}$ College of Medical, Veterinary and Life Sciences, University of Glasgow, Glasgow, UK; ${ }^{2}$ National CJD Surveillance Unit, University of Edinburgh, Edinburgh, UK

Introduction The potential for vCJD transmission in the healthcare setting has raised concerns over the risk posed by dental surgery. The aim of this study was to determine whether dental treatment was a possible risk factor for vCJD, by looking for links between vCJD cases and whether there was an excess of dental treatment in vCJD cases compared with general population controls.

Methods Dental treatment records were collected from general dental practitioners or, where this was not possible, from NHS Dental Practice Board payment schedules.

Results Data were available for $49 \%(79 / 162)$ of cases and $82 \%$ $(503 / 610)$ of controls. Two pairs of cases had received dental treatment at the same dental practice, however the type and timing of recorded interventions did not provide strong evidence that this was how vCJD was acquired. The review of specific dental treatments also showed that there was no evidence that vCJD cases experienced an excess of any type of dental treatment compared with controls.

Conclusions This study provided no compelling evidence of a strong association between dental treatment and $\mathrm{vCJD}$, however because of the limited availability of dental information, and the possibility of undetected asymptomatic infection, we cannot exclude dental treatment as a possible risk factor for vCJD. We recommend the development of more portable and robust mechanisms for dental record keeping in the UK that are also useable for public health purposes, and support current health policy to ensure that high standards of cleaning and sterilisation of re-usable dental instruments are maintained.

\section{SP3-36 UTILISATION OF MATERNAL HEALTH SERVICES AMONG WOMEN OF REPRODUCTIVE AGE GROUP IN A RURAL DISTRICT, SOUTHERN NIGERIA}

doi:10.1136/jech.2011.1429760.36

${ }^{1} \mathrm{M}$ Agogbuo, ${ }^{*} \mathrm{~S}$ Akpovi, ${ }^{3} \mathrm{~N}$ Achime, ${ }^{4} \mathrm{~S}$ Bello. ${ }^{1}$ University of Calabar Teaching Hospital, Calabar, Cross River, Nigeria; ${ }^{2}$ University of Benin, Benin City, Edo State, Nigeria; ${ }^{3}$ University of Benin, Benin City, Edo State, Nigeria; ${ }^{4}$ University of Calabar Teaching Hospital, Calabar, Cross River, Nigeria

Introduction The Maternal mortality ratio is unacceptably high in Nigeria. A major remote cause of maternal death in Nigeria is poor utilisation of health services by women of reproductive age group. This study sought to determine the level of utilisation and factors associated with the use of maternal health services among women of reproductive age group in Egor LGA of Edo State.

Methodology A cross-sectional descriptive survey was carried out among 349 respondents in four communities. A multistage sampling technique was used to select respondents from whom data were collected using a pre-tested, interviewer-administered, semi-structured questionnaire and an observational checklist. Factors were identified with bivariate and multivariate analysis.

Results The greatest preference was for Traditional Birth Attendants $(52.2 \%)$, followed by health centre $(43.5 \%)$. Reasons for preference of choices included cheap cost (52.6\%) and safety (37.8\%). Reasons for dissatisfaction with services at the health centre were: lack of doctors $(54.0 \%)$, poor attitude of health workers $(27.2 \%)$ and lack of drugs (13.6\%). At bivariate analysis, factors that were significantly associated with utilisation were: respondents' education $(p<0.0001)$, occupation $(p<0.0001)$, distance of respondents' home from health facility $(p<0.0001)$ and perception of adequacy of sitting of health facility $(\mathrm{p}<0.0001)$. Farmers (Adjusted OR, AOR $0.28,95 \%$ CI 0.13 to 0.61 ) and the unemployed (AOR $0.28,95 \% \mathrm{CI}$ 0.10 to 0.78 ) were less likely to patronise health centres than civil servants.

Conclusion Jobs should be created to increase earning capacity of residents of Edo State in order to improve utilisation of maternal health services.

\section{SP3-37 TOBACCO SMOKING IN BRAZIL: REGIONAL INEQUALITIES AND PREVALENCE ACCORDING TO OCCUPATIONAL CHARACTERISTICS}

doi:10.1136/jech.2011.1429760.37

A M Cascaes, ${ }^{*}$ F C Wehrmeister, J Martínez-Mesa, A M B Menezes, A J D Barros. Federal University of Pelotas, Pelotas, Rio Grande do Sul, Brazil

Introduction Tobacco smoking is a great public health problem. Its evaluation and monitoring is important to identify risk groups and help guiding public policies.

Objectives To describe the prevalence of daily tobacco smoking according to sex, age, per capita household income and occupation of residents over 15-year old in Brazil and macro-regions.

Methods We analysed data of 252.768 individuals from the 2008 Brazilian National Survey, the Pesquisa Nacional por Amostragem de Domicilios (PNAD/IBGE). The analysis was adjusted for the sampling design. Multivariate Poisson regression models were used to associate occupational variables to smoking.

Results Daily smoking prevalence in Brazil was $15.1 \%$, varying from $12.0 \%$ in North region to $17.4 \%$ in Southern region, and was $62.0 \%$ higher in men compared to women. Higher proportion of male smokers was between 50 and 59 years old and in women the peak was from 40 to 49 years old. Smoking was inversely proportional to household income, varying from $11.5 \%$ among the $20 \%$ richest to $18.6 \%$ among the $20.0 \%$ poorest. Same trends for gender, age and income were observed in the different regions of Brazil. Daily cigarette consumption was $32.0 \%$ higher among workers compared to non-workers. White collar workers presented a smoking prevalence below $10.0 \%$, while blue collar workers had rates above $20.0 \%$. The association between smoking and occupation remained after the adjustment for sex, age and household income $(\mathrm{p}<0.001)$

Conclusions the inequalities found should be considered when developing effective strategies to smoking control and cessation. The occupational groups more exposed should have priority in the interventions. 